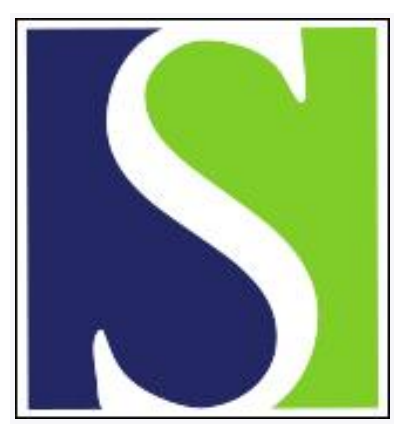

Scand J Work Environ Health 1997;23(1):54-59

https://doi.org/10.5271/sjweh.179

Issue date: Feb 1997

Effects of work-related stress reduction on depressive symptoms among Japanese blue-collar workers

by Kawakami N, Araki S, Kawashima K, Masumoto T, Hayashi T

The following article refers to this text: 2009;35(1):7-18

Key terms: blood pressure; intervention study; Japan; program evaluation; sick leave; work stress

This article in PubMed: www.ncbi.nlm.nih.gov/pubmed/9098913

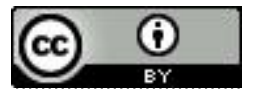




\title{
Effects of work-related stress reduction on depressive symptoms among Japanese blue-collar workers
}

\author{
by Norito Kawakami, MD, ${ }^{1}$ Shunichi Araki, MD, ${ }^{2}$ Mieko Kawashima, MHSc, ${ }^{3}$ Takeshi Masumoto, MD, ${ }^{4}$ \\ Takeshi Hayashi, $M D^{5}$
}

\begin{abstract}
Kawakami N, Araki S, Kawashima M, Masumoto T, Hayashi T. Effects of work-related stress reduction on depressive symptoms among Japanese blue-collar workers. Scand J Work Environ Health 1997;23:54-9.
\end{abstract}

\begin{abstract}
Objectives The effects of a stress reduction program on Japanese blue-collar workers were investigated using a controlled trial design.

Methods Two blue-collar worksites that showed higher depression scores (Zung self-rating depression score) were selected for the intervention group, after a survey of a large electric company in 1985 . Three blue-collar worksites were selected as a reference group whose workers were matched with the workers of the interventive worksites by mean age, worksite size and mean depression scores. A 1-year stress reduction program was conducted in the intervention group from 1986 to 1987 by worksite supervisors. Effects of the stress reduction program were assessed by comparing the initial depression scores, length of sick leave, and systolic and diastolic blood pressures with those after the follow-up.

Results The depression scores decreased during the follow-up in the intervention group, while the scores were almost the same in the reference group. An analysis of covariance with repeated measurements indicated a statistically significant intervention (group $\times$ time interaction) effect after control for gender and age $(P=0.035)$. Sick leave in the past year decreased in 1988 only in the intervention group; generalized logit analysis with repeated measurements indicated a statistically significant intervention effect after control for gender and age $(\mathrm{P}=0.034)$. No statistically significant intervention effects were observed on systolic and diastolic blood pressures or selected work stressors.

Conclusions A stress reduction program directed towards worksite supervisors can be used to reduce depressive symptoms and sick leave among Japanese blue-collar workers.
\end{abstract}

Key terms blood pressure, intervention study, Japan, program evaluation, sick leave, work stress.

Previous studies have clarified adverse effects of work stress on health among workers (1). Reducing work stress is important in preventing stress-related diseases and promoting worker health in industry. Stress reduction programs directed towards the work environment and organizational approaches, such as job redesign, have been emphasized as a useful approach $(1-3)$. Karasek \& Theorell (1) have suggested that increased job control or autonomy is a key factor for job redesign to reduce job strain and increase productivity.

In contrast to approaches centered on the individual worker, such as physical fitness programs and relaxation and cognitive therapy, the effects of approaches oriented towards the work environment are less clear however (2). Work redesign studies have been conducted with blue-collar (4) and white-collar workers (5), and with both significant improvement was observed in job characteristics and worker satisfaction after the intervention. A report from the International Labour Office also included 19 case studies on the prevention of stress at work from 9 countries (6); 14 were oriented toward stress reduction in the work environment, using such methods as task or job redesign and organizational restructuring, including both expert guidance and worker participation.

Reprint requests to: Dr N Kawakami, Department of Public Health, Gifu University School of Medicine, 40 Tsukasa-machi, Gifu, Gifu 500, Japan. E-mail: norito@cc.gifu-u.ac.jp

Department of Public Health, Gifu University School of Medicine, Gifu, Japan.

Department of Public Health, Faculty of Medicine, University of Tokyo, Tokyo, Japan.

Department of Mental Health and Nursing, School of Health Sciences and Nursing, University of Tokyo, Tokyo, Japan.

Nippon Kokan Hospital, NKK Corporation, Kawasaki, Japan.

Hitachi Health Care Center, Hitachi, Ltd, Ibaraki, Japan. 
However, in 6 of these studies, the evaluation of the programs was anecdotal or based on assessments made only after the program. Nine included efforts to assess some measures before and after the programs (4-6). Since these studies had no reference group, the effects of "regression to the mean" or natural course of stressors or symptoms could not be ruled out (7). A study reported significant improvement in the level of serum lipoproteins after stress reduction activity in an intervention group, in comparison with a reference group $(8,9)$. However, the 2 groups had different base-line levels of serum lipoproteins and work-related factors, and these differences may have been a source of confounding bias. A randomized controlled trial on a work unit (10) demonstrated the effects of worker participation in decision making (ie, increased frequency of unit meetings) on a decrease in work stressors, emotional strain, and turnover intent to change jobs. Unfortunately, the data were incompletely presented for some of the participants, and the authors did not show the full analysis with which to assess the intervention effects. Evidence from research using an appropriate epidemiologic study design, such as a controlled experimental trial, is still needed to establish stress reduction through the effects of a program oriented towards the work environment.

Most previous studies on work stress reduction have assessed acute stress reactions as outcome measures, namely, psychological (eg, anxiety or depression), physiological (eg, blood pressure), and behavioral (eg, smoking, absenteeism, turnover rate) reactions, as well as specific work stressors $(1-6,8-10)$, since a much longer follow-up period is required to observe the onset of illness. Measures of psychological distress and subjective symptoms have been the most frequently used $(3,5,6$, 10 ), and the studies have generally suggested that these measures are sensitive to a stress reduction program oriented towards the work environment. Fewer studies have included physiological outcome measures $(8,9)$, sick leave, and actual turnover rate (6). The use of these objective outcome measures, together with psychological distress measures, has been recommended to help the evaluation of work stress reduction programs (2).
We conducted a controlled study in a large electric company in Japan to determine the effects of a stress reduction program oriented towards the work environment of Japanese blue-collar workers with the cooperation of worksite supervisors and the corporate medical staff. Our primary aim was to determine the effects of the stress reduction program on any decrease in depressive symptoms as a psychological distress measure. We also examined changes in systolic and diastolic blood pressures and sick leave during the stress reduction program.

\section{Subjects and methods}

\section{Subjects}

A company-wide work stress survey was conducted in a large electric company $(\mathrm{N}=1500)$ in Japan in October 1985 using the Zung self-rating depression scale (SDS) $(11,12)$. The study feasibility limited the intervention program to several worksites, and our primary interest was in developing the program for blue-collar workers. Among worksites with mean depression scores higher than the mean plus 1 standard deviation for the entire sample in this survey, the 2 worksites (111 workers) that first appeared in the worksite directory were selected for the intervention group (table 1). Other worksites were selected for the reference group, matched for mean age (within 5 years), major products and occupations, worksite size ( $50-70$ workers), and mean depression scores in 1985 (within 3 depression scores) with the intervention worksites. Three worksites (183 workers) fulfilled these criteria. A 1-year worksite intervention program was conducted (November 1986 - October 1987) in the intervention group. No particular activity reducing work stress was conducted in the reference group. To assess the effects of the program, we conducted surveys at the beginning of the study (October 1986) and on 2 followup occasions (October 1987 and October 1988), using the same questionnaire concerning depressive symptoms, sick leave, and work stressors. In the intervention group

Table 1. Characteristics of the intervention and reference groups.

\begin{tabular}{|c|c|c|c|c|c|c|c|c|c|c|c|c|c|c|c|}
\hline \multirow[b]{4}{*}{$\begin{array}{l}\text { Intervention } \\
\text { group (2 } \\
\text { worksites) }\end{array}$} & \multicolumn{8}{|c|}{ Worksite characteristics in 1985} & \multirow{3}{*}{$\begin{array}{l}\text { Number of } \\
\text { respondents } \\
\text { at the } \\
\text { beginning } \\
\text { of the } \\
\text { intervention } \\
\text { in } 1986\end{array}$} & \multicolumn{6}{|c|}{ Respondents followed for 2 years } \\
\hline & \multirow{2}{*}{$\begin{array}{c}\text { Number } \\
\text { of } \\
\text { workers }\end{array}$} & \multirow{2}{*}{$\begin{array}{c}\text { Mean } \\
\text { depression } \\
\text { score }\end{array}$} & \multicolumn{2}{|c|}{ Men } & \multicolumn{2}{|c|}{ Age (years) } & \multirow{2}{*}{$\begin{array}{c}\text { Major } \\
\text { production }\end{array}$} & \multirow{2}{*}{$\begin{array}{c}\text { Main } \\
\text { occupation }\end{array}$} & & \multicolumn{2}{|c|}{ Follow-up rate } & \multicolumn{2}{|c|}{ Men } & \multicolumn{2}{|c|}{ Age (years) } \\
\hline & & & N & $\%$ & Mean & $\mathrm{SD}$ & & & & N & $\%$ & N & $\%$ & Mean & SD \\
\hline & 111 & 41.6 & 84 & 76 & 33 & 12 & $\begin{array}{l}\text { Micro- } \\
\text { circuits }\end{array}$ & $\begin{array}{l}\text { Machine } \\
\text { operators and } \\
\text { technicians }\end{array}$ & 110 & 79 & 72 & 67 & 85 & 32 & 11 \\
\hline $\begin{array}{l}\text { Reference } \\
\text { group (3 } \\
\text { worksites) }\end{array}$ & 186 & 40.6 & 104 & 56 & 35 & 12 & $\begin{array}{l}\text { Microcircuits } \\
\text { and electric } \\
\text { cables }\end{array}$ & $\begin{array}{c}\text { Machine } \\
\text { operators } \\
\text { and technicians }\end{array}$ & 175 & 108 & 62 & 63 & 58 & 33 & 12 \\
\hline
\end{tabular}


4 workers quit working for the company during the follow-up and 27 did not complete the follow-up questionnaires; 15 workers quit and 52 workers did not complete the questionnaires in the reference group. The analysis was based on data from 79 respondents in the intervention group and 108 respondents in the reference group, who were completely followed for the 2 -year period. The follow-up rate was slightly lower in the reference group. The intervention group included a higher proportion of male workers than did the reference group.

\section{Stress reduction program}

A 1-year worksite stress reduction program was conducted in the intervention group from 1986 to 1987. The corporate medical staff proposed a stress reduction program for the selected worksite in the company. The company agreed and organized a working committee which included 5 worksite supervisors, corporate medical staff (a mental health professional, an industrial physician, 3 public health nurses, 2 psychologists) and 3 of the personnel. First, in August and September 1986, the medical staff explained the work stress survey results to the supervisors, emphasized the need for a stress reduction program for their worksites, and invited them to join the study. Second, in meetings in October and November 1986, the supervisors were asked to list possible work stressors in their worksites. Then, in November 1986, they were asked to make possible plans to reduce these stressors. During this process, the committee worked together to make feasible and effective plans. Finally, the supervisors started stress reduction activities that lasted from November 1986 to October 1987. The committee monitored their activity periodically and had another meeting at the end of the 1-year activity, while the stress reduction activity continued after October 1987.

Several possible work stressors were reported for the intervention group by the supervisors. First, additional overtime was often required because of poor performance of production machines. Therefore the machine speed and performance were mechanically improved. Second, production machines required workers to check many points before starting them and after stopping them (reported as a possible source of job demand). Therefore a reduction in the number of checkpoints was planned by the supervisors and carried out through a small group activity for quality control. Third, rapid technological changes in the production process of electrical circuits tended to make worker skills out of date and insufficient. Therefore, promotion of "on-the-job" training and standardization of the production process were proposed. But these were not fully implemented during the 1-year intervention period. Fourth, the supervisors reported that the number of workers assigned to a supervisor might be too many to be sufficiently managed, controlled, and cared for and that workers had little chance to talk to their direct supervisor. Therefore plans were made to train and place additional subleaders between a supervisor and coworkers to manage smaller work units within each workplace. The proposal was accepted by the company and conducted during the intervention period. No other organizational changes were reported from the company during the follow-up period.

\section{Outcome measures}

We included the following 4 measures of health outcomes: depressive symptoms, sick leave, and systolic and diastolic blood pressure. We measured the depression score (Zung's SDS score) and the self-reported length of sick leaves in the past year using a questionnaire at the beginning of the study (in 1986) and at the 1- and 2-year follow-ups (in 1987 and 1988, respectively). Although we used a slightly modified version of the Japanese SDS (13), the psychometric properties have proved to be same as those for the original SDS (14). The length of sick leaves was categorized into 3 levels (ie, none, $1-5 \mathrm{~d}$ and $\geq 6 \mathrm{~d}$ in the past year). The systolic and diastolic blood pressures were measured in the beginning of the study and at the 2-year follow-up. The following 6 work stressors were similarly assessed using the questionnaire: overtime, work overload, little chance to learn new knowledge, lack of control over workplace and interpersonal problems with supervisor and co-workers. These work stressors were dichotomized $(15,16)$. The proportion of those who worked overtime more than $30 \mathrm{~h}$ per month or those who had higher stress on each work stressor was calculated.

\section{Statistical analysis}

The depression score and blood pressures were almost normally distributed. An analysis of covariance (ANCOVA) of repeated measurements was used to assess the intervention effect on the depressive symptoms and blood pressures. For the depression score, the statistical significance for an interactive effect between the group (intervention or reference) and time (1986, 1987 or 1988) was assessed with control for gender and age, where age was entered as a continuous covariate. Similarly, the statistical significance of an interactive effect between the groups and time (1986 or 1988) on systolic and diastolic blood pressure was assessed with control for gender and age. These analyses were conducted using the GLM procedure of the SAS version 6.04 on a PC (17). Generalized logit analysis with repeated measurements was used to assess the intervention effect on sick leave and the 6 work stressors. For sick leave the statistical significance for an interactive term between the group and time (1986, 1987 or 1988) was assessed with control for gender and age group, where the 3 categories for sick leave were considered as an ordered variable and age was dichotomized into $\leq 29$ years and $\geq 30$ years. 
The statistical significance of the intervention (group $x$ time) effect on each of the 6 work stressors was similarly assessed. These analyses were conducted using the CATMOD procedure of the SAS version 6.04 on a personal computer (17).

\section{Results}

The depression scores decreased after the intervention program in the intervention group, while the scores were almost stable in the reference group (table 2). A statistically significant intervention effect on depression scores was observed. Systolic and diastolic blood pressures were almost the same for the intervention and reference groups at the beginning of the study and in 1988. The intervention effects were not statistically significant.

The proportion of those who had $1-5$ days of sick leave in the past year decreased in 1988 in the intervention group (table 3). A statistically significant interven- tion effect was observed, while there was also a statistically significant main effect for the group difference in the length of sick leave between the groups [generalized logit analysis, chi-square $=18.4$, degrees of freedom (df $)=2, P<0.001]$. The proportion of those who worked overtime for $\geq 30 \mathrm{~h}$ per month increased in 1987 and 1988 in the intervention group. However, the proportion of those who felt little chance to learn new knowledge decreased in 1987 in the intervention group. The intervention effect was marginally significant for overtime. The intervention effects were not statistically significant for the other work stressors.

For the male subjects, a statistically significant intervention effect was observed for the depression score (ANCOVA with repeated measurements, $\mathrm{df}=2, \mathrm{~F}=$ $4.96, \mathrm{P}=0.025)$, the mean depression scores being 41.1 (SD 7.9), 39.6 (SD 7.1), and 38.6 (SD 6.4) in 1986, 1987 and 1988, respectively, for the intervention group $(\mathrm{N}=67)$ and $41.5(\mathrm{SD} 7.1), 41.8(\mathrm{SD} 7.2)$, and 42.3 (SD 8.0) for the reference group $(\mathrm{N}=63)$. For the female subjects, the intervention effect was not statistically sig-

Table 2. Depression score and systolic and diastolic blood pressure in the intervention $(N=79)$ and reference $(N=108)$ groups. ${ }^{a}$

\begin{tabular}{|c|c|c|c|c|c|c|c|c|c|}
\hline & \multicolumn{3}{|c|}{ Depression score } & \multicolumn{3}{|c|}{$\begin{array}{l}\text { Systolic blood pressure } \\
(\mathrm{mm} \mathrm{Hg})^{\mathrm{b}}\end{array}$} & \multicolumn{3}{|c|}{$\begin{array}{l}\text { Diastolic blood pressure } \\
(\mathrm{mm} \mathrm{Hg})^{\mathrm{b}}\end{array}$} \\
\hline & Mean & SD & Range & Mean & $\mathrm{SD}$ & Range & Mean & SD & Range \\
\hline \multicolumn{10}{|l|}{ Base line (1986) } \\
\hline $\begin{array}{l}\text { Intervention group } \\
\text { Reference group }\end{array}$ & $\begin{array}{l}41.4 \\
41.2\end{array}$ & $\begin{array}{l}7.7 \\
7.1\end{array}$ & $\begin{array}{l}27-71 \\
23-59\end{array}$ & $\begin{array}{l}130.2 \\
130.9\end{array}$ & $\begin{array}{l}18.8 \\
13.9\end{array}$ & $\begin{array}{r}90-198 \\
102-162\end{array}$ & $\begin{array}{l}72.5 \\
73.5\end{array}$ & $\begin{array}{l}14.5 \\
11.3\end{array}$ & $\begin{array}{l}36-120 \\
48-104\end{array}$ \\
\hline \multicolumn{10}{|c|}{ One-year follow-up (1987) } \\
\hline $\begin{array}{l}\text { Intervention group } \\
\text { Reference group }\end{array}$ & $\begin{array}{l}39.7 \\
41.2\end{array}$ & $\begin{array}{r}71.1 \\
6.5\end{array}$ & $\begin{array}{l}21-64 \\
28-56\end{array}$ & $\begin{array}{l}. . \\
. .\end{array}$ & $\begin{array}{l}. . \\
. .\end{array}$ & $\begin{array}{l}. . \\
. .\end{array}$ & $\begin{array}{l}. . \\
. .\end{array}$ & $\begin{array}{l}. . \\
. .\end{array}$ & $\begin{array}{l}. . \\
. .\end{array}$ \\
\hline \multicolumn{10}{|c|}{ Two-year follow-up (1988) } \\
\hline $\begin{array}{l}\text { Intervention group } \\
\text { Reference group }\end{array}$ & $\begin{array}{l}38.6 \\
41.0\end{array}$ & $\begin{array}{l}6.4 \\
7.3\end{array}$ & $\begin{array}{l}27-66 \\
24-57\end{array}$ & $\begin{array}{l}125.8 \\
128.3\end{array}$ & $\begin{array}{l}17.8 \\
13.8\end{array}$ & $\begin{array}{r}100-188 \\
94-160\end{array}$ & $\begin{array}{l}70.8 \\
73.4\end{array}$ & $\begin{array}{l}14.2 \\
11.4\end{array}$ & $\begin{array}{l}38-116 \\
46-110\end{array}$ \\
\hline
\end{tabular}

a Intervention (ie, group $x$ time) effects on an analysis of covariance with repeated measurements controlling for gender and age groups: $F=3.41, \mathrm{df}=2$, $P=0.035$ for depressive symptoms; $F=0.01, d f=1, P=0.906$ for systolic blood pressure; $F=0.00, d f=1, P=0.966$ for diastolic blood pressure. (df = degree of freedom)

b $1 \mathrm{~mm} \mathrm{Hg} \approx 0.133 \mathrm{kPa}$

Table 3. Sick leave in the past year and work stressors in the intervention $(N=79)$ and reference $(N=108)$ groups.

\begin{tabular}{|c|c|c|c|c|c|c|c|}
\hline \multirow[t]{2}{*}{ Variable } & \multicolumn{3}{|c|}{$\begin{array}{l}\text { Intervention group } \\
(\%)\end{array}$} & \multicolumn{3}{|c|}{$\begin{array}{l}\text { Reference group } \\
(\%)\end{array}$} & \multirow{2}{*}{$\begin{array}{l}\text { Intervention } \\
\text { (group x time) } \\
\text { effecta }^{\mathrm{a}}\end{array}$} \\
\hline & 1986 & 1987 & 1988 & 1986 & 1987 & 1988 & \\
\hline \multicolumn{8}{|l|}{ Sick leave in the past year } \\
\hline $\begin{array}{l}\text { None } \\
1-5 \text { days } \\
\geq 6 \text { days }\end{array}$ & $\begin{array}{r}40 \\
52 \\
8\end{array}$ & $\begin{array}{r}37 \\
61 \\
2\end{array}$ & $\begin{array}{r}61 \\
34 \\
5\end{array}$ & $\begin{array}{l}53 \\
33 \\
14\end{array}$ & $\begin{array}{l}52 \\
37 \\
11\end{array}$ & $\begin{array}{r}58 \\
37 \\
5\end{array}$ & $10.4(P=0.034)$ \\
\hline Overtime (more than $30 \mathrm{~h}$ per month) & 44 & 71 & 78 & 57 & 55 & 57 & $3.0(P=0.229)$ \\
\hline \multicolumn{8}{|l|}{ Self-reported work stressors } \\
\hline $\begin{array}{l}\text { Work overload } \\
\text { Little chance to learn new knowledge } \\
\text { Lack of control over workpace } \\
\text { Problems with supervisor } \\
\text { Problems with co-workers }\end{array}$ & $\begin{array}{l}26 \\
17 \\
26 \\
24 \\
15\end{array}$ & $\begin{array}{r}42 \\
7 \\
23 \\
30 \\
15\end{array}$ & $\begin{array}{r}43 \\
8 \\
21 \\
24 \\
13\end{array}$ & $\begin{array}{r}28 \\
11 \\
26 \\
29 \\
9\end{array}$ & $\begin{array}{l}26 \\
10 \\
28 \\
34 \\
12\end{array}$ & $\begin{array}{r}26 \\
8 \\
22 \\
34 \\
16\end{array}$ & $\begin{array}{l}5.9(P=0.054) \\
2.1(P=0.355) \\
2.3(P=0.311) \\
3.2(P=0.204) \\
0.9(P=0.633)\end{array}$ \\
\hline
\end{tabular}

a Generalized logit analysis with repeated measurements controlling for gender and age groups. Chi-square value with P-value in parentheses (degrees of freedom: 4 for sick leave and 2 for others). 
nificant (ANCOVA with repeated measurements, $\mathrm{df}=2$, $\mathrm{F}=0.34, \mathrm{P}=0.716)$, the mean depression scores being 41.6 (SD 7.1), 40.4 (SD 8.8) and 41.1 (SD 9.7) in 1986, 1987 and 1988, respectively, for the intervention group $(\mathrm{N}=12)$ and 40.7 (SD 6.8), 40.3 (SD 5.3) and 39.1 (SD $5.7)$ for the reference group $(\mathrm{N}=45)$. No clear difference in the intervention effects on blood pressure, sick leave, or the work stressors was observed between the men and women.

At the beginning of the study the female workers were significantly more likely to be lost to follow-up than the male workers in the intervention group (logistic regression, chi-square $=15.7, \mathrm{df}=1, \mathrm{P}<0.001$ ), but not in the reference group (logistic regression, chisquare $=0.1, \mathrm{df}=1, \mathrm{P}=0.746$ ). Older workers were significantly more likely to be lost to follow-up than younger workers in both the intervention and the reference groups (logistic regression, chi-square $=7.5, \mathrm{df}=1$, $\mathrm{P}=0.006$ and chi-square $=4.3, \mathrm{df}=1, \mathrm{P}=0.037$, respectively). The initial depression score, blood pressure, sick leave, and work stressors were not statistically significantly associated with being lost to follow-up in the intervention or reference groups (logistic regression, $\mathrm{P}>0.05)$.

\section{Discussion}

Our study demonstrated decreases in depressive symptoms and sick leave in the intervention group. This result suggests that a stress reduction program oriented toward the work environment can be useful to improve depressive symptoms and sick leave among Japanese bluecollar workers. The intervention group had a lower proportion of female workers than the reference group, and the older and female subjects were more likely to be lost to follow-up. The intervention group also had more days of sick leave at the beginning of the study. However, we found statistically significant intervention effects on depressive symptoms and sick leave even after control for gender, age, and the initial levels. Thus these findings are not likely biased due to confounding or attrition associated with gender, age, or the base-line difference. The assessments of depressive symptoms and sick leave were self-reported but made as part of company-wide stress surveillance. Thus information bias is less likely to have affected the results. The results from our controlled study are consistent with previous findings of the effectiveness of stress reduction programs oriented towards the work environment (4-6, 8-10), and they provide more concrete evidence than previous anecdotal and uncontrolled studies (4-6). Our experimental study also provides additional evidence of the effects of work stressors on depressive symptoms and sick leave, as has already been suggested by observational epidemiologic studies (1).
Since our study was not a randomized controlled trial, we could not rule out a possible confounding effect of other factors, such as a difference in social structures between the groups. Future research should use a randomized controlled trial design to avoid such unknown confounders.

Although corporate medical staff encouraged and assisted the supervisors during the planning phase, the supervisors played an essential role in our stress reduction program. Although, at the very beginning, they were somewhat reluctant, the supervisors generally showed their ability to recognize psychosocial stressors or problems at their worksites and to build feasible plans during the planning phase. Our study suggests the importance of involving and training supervisors in stress reduction programs oriented towards the work environment. We have more vertical hierarchies, structures, and close supervisory styles in Japanese industry than, for example, in the United States $(18,19)$. Such organizational characteristics in Japan might enhance the effects of our stress reduction program involving worksite supervisors. It is also possible that a substantial improvement can be attained if stress reduction programs are constructed to include regular workers in the planning phase also.

Our stress reduction program failed to produce any changes in the systolic and diastolic blood pressure values. This result may be due to the fact that most of the subjects $(71 \%)$ in the intervention group had normal blood pressure values [ie, systolic blood pressure $<140$ $\mathrm{mm} \mathrm{Hg}(<55.9 \mathrm{kPa})$ and diastolic blood pressure $<90$ $\mathrm{mm} \mathrm{Hg}(<12.0 \mathrm{kPa})]$. A few epidemiologic studies have shown a statistically significant association between job strain and casual blood pressure (20). Thus our finding may be due to the use of casual blood pressure readings. However, our primary focus on depressive symptoms may have resulted in fewer effects on blood pressure. Our previous studies found that lack of control over workplace, unsuitable jobs, and lack of social support at the worksite were associated with depressive symptoms (15), while another work stressor (ie, complicated machine operation) was associated with increased blood pressure (21). Different aspects of task characteristics and the work environment may be important for blood pressure. Future research on work stress reduction should pay more attention to the effects on multiple outcome measures.

Depression among the female workers in the intervention group did not change during the follow-up. Our previous study has suggested that the remission rate from depression is equal for male and female employees (14). This finding is probably not due to the female tendency to have persistent depression. Our intervention program may have been less effective for female workers. The worksite supervisors, who had an important role in our program, were all men, and most of the workers in the 
intervention workplaces were men. The supervisors might consider male workers a major target population for which to plan and conduct stress reduction activities. Future stress reduction activity should be aware of work stress and problems for both genders.

The proportion of those who worked overtime more than $30 \mathrm{~h}$ per month tended to increase during the follow-up. The intervention worksites actually faced a higher demand from the market during the first year of follow-up, which was an unexpected coincidence. The demand only occurred for a special type of electric circuit, which happened to be a major product of the intervention group worksites; this was not the case for the reference group. Increased overtime could have been due to such a special situation during the follow-up. Another possible explanation is that the intervention program caused additional overtime because of the extra work needed for the reform of tasks and organization. This possibility is less likely since the company did not agree to pay workers for extra hours for stress reduction. A slight but statistically nonsignificant decrease in the proportion of those who felt little chance to learn new knowledge in the intervention group may be due to the increase in small group activities, the "on-the-job" training, and the technical support from new subleaders. The decrease in the depression scores and amount of sick leave, despite an increase in overtime, in the intervention group agrees with the prediction of the job demand-control model (1) that states that increases in both job demands and control (including skill discretion) lead to less job strain and more stimulation for development (ie, an "active" job). However, since no intervention effect on the work stressors reached a statistically significant level, the decreases in the depression scores and sick leave are not fully explained by changes in these work stressors. The selected questions on work stressors only covered a very limited area of work stress and may have failed to assess important psychosocial improvements achieved through the intervention program. More standardized measures of work stressors should be included in future research.

\section{References}

1. Karasek R, Theorell T. Healthy work. New York (NY): Basic Books, 1990.

2. Hurrell JJ Jr. An overview of organizational stress and health In: Murphy LR, Schoenborn TF, editors. Stress management in work settings. New York (NY): Praeger, 1989:31

3. Westlander G. Organizational change and health at work. In: Johnson JV, Johansson G, editors. Psychosocial work environment. New York (NY): Baywood Publishing, 1991:133.

4. Wall TD, Clegg CW. A longitudinal field study of group work redesign. J Occup Behav 1981:2:31 - 49.

5. Wallin L, Wright I. Psychosocial aspects of the work environment: a group approach. J Occup Med 1986;28:384—93.

6. Karasek R. Stress prevention through work reorganization: a summary of 19 international case studies. ILO conditions of work digest: preventing stress at work. 1992;11(2):23-41.

7. Fletcher RH, Flethcer SW, Wagner EH. Clinical epidemiology. 2nd ed. Baltimore (MD): Williams \& Wilkins, 1988:129.

8. Eriksson I, Moser V, Unden A-L, Orth-Gomer K. Using knowledge and discussion to decrease stress in Swedish public administration officials. ILO conditions of work digest: preventing stress at work 1992;11(2):214-9.

9. Orth-Gomer K, Eriksson I, Moser V, Theorell T, Fredlund P. Lipid lowering through work stress reduction. Int J Behav Med 1994:1:204-14.

10. Jackson S. Participation in decision making as a strategy for reducing job-related strain. J Appl Psychol 1983;68:3-19.

11. Zung WWK. A self-rating depression scale. Arch Gen Psychiatry 1965;12:63-70.

12. Zung WWK. A cross-cultural survey of symptoms in depression. Am J Psychiatry 1969;126:116-21.

13. Fukuda K, Kobayashi S. A study on a self-rating depression scale [in Japanese]. Psychiatr Neurol Jpn 1973;75:673—9.

14. Kawakami N, Roberts RE, Lee YS, Araki S. Changes in rates of depressive symptoms in a Japanese working population: a life-table analysis from a four-year follow-up study. Psychol Med 1995;25:1181-90.

15. Kawakami N, Araki S, Kawashima M. Effects of job stress on occurrence of major depression in Japanese industry: a casecontrol study nested in a cohort study. J Occup Med 1990; 32:722-5.

16. Kawakami N, Haratani T, Araki S. Effects of perceived job stress on depressive symptoms in blue-collar workers of an electrical factory in Japan. Scand J Work Environ Health 1992;18:195-200.

17. SAS Institute, Inc. SAS user's guide. Cary (NC): SAS Institute, Inc, 1988.

18. Nakane C. Japanese society. Berkeley (CA): University of California Press, 1970.

19. Lincoln JR, Kalleberg AL. Culture, control, and commitment: a study of work organization and work attitudes in the United States and Japan. Cambridge: Cambridge University Press, 1990.

20. Schnall PL, Landsbergis PA. Job strain and cardiovascular disease. Annu Rev Public Health 1994;15:381 - 411.

21. Kawakami N, Haratani T, Kaneko T, Araki S. Perceived jobstress and blood pressure increase among Japanese blue-collar workers: one-year follow-up study. Ind Health 1989;27:7181 .

Received for publication: 9 November 1995 